\title{
Estrogen Stimulates Postsynaptic Density-95 Rapid Protein Synthesis via the Akt/Protein Kinase B Pathway
}

\author{
Keith T. Akama and Bruce S. McEwen \\ Harold and Margaret Milliken Hatch Laboratory of Neuroendocrinology, The Rockefeller University, New York, New York 10021-6399
}

Estrogens induce synaptogenesis in the CA1 region of the dorsal hippocampus during the estrous cycle of the female rat. Functional consequences of such estrogen-mediated synaptogenesis include cyclic changes in neurotransmission and memory. At the molecular level, estrogen stimulates the rapid activation of specific signal transduction pathways, and of particular interest is the activation of Akt (protein kinase B), a key signal transduction intermediate that initiates protein translation by alleviating the downstream translational repression of eukaryotic initiation factor 4E-binding protein 1 (4E-BP1). Using a well established in vitro model system of differentiated NG108-15 neurons to investigate such rapid signaling effects of estrogen, we show that estrogen stimulates the phosphorylation of Akt, an indication of kinase activation, as well as the phosphorylation of 4E-BP1. In turn, the activation of these signaling intermediates suggests a non-genomic mechanism by which estrogen might likewise lead to protein translation of dendrite-localized mRNA transcripts in the hippocampus in vivo. We therefore considered the translation of the dendritic spine scaffolding protein postsynaptic density-95 (PSD95). Although estrogen does not stimulate a rapid increase in PSD-95 mRNA levels in NG108-15 neurons, we show here that estrogen does however stimulate a rapid increase in PSD-95 new protein synthesis in vitro and that this new protein synthesis is Akt dependent. These results demonstrate an essential role for Akt in estrogen-stimulated dendritic spine protein expression, describe for the first time a signal transduction pathway in PSD-95 expression, and delineate a novel, molecular mechanism by which ovarian hormones might translationally regulate synaptogenesis via activating protein synthesis for dendritic function.

Key words: estrogen; hippocampus; synaptogenesis; dendritic spine; protein translation; local protein synthesis; signal transduction; eIF4E-BP1

\section{Introduction}

Estradiol $17 \beta$ (E) plays a major role in the cyclic increases in dendritic spine density and synaptogenesis in the CA1 region of the rat hippocampus across the estrous cycle (Woolley and McEwen, 1992). Likewise, exogenous administration of E to ovariectomized female rats also increases spine density and synaptogenesis (Gould et al., 1990) and demonstrates how ovarian hormones can drive structural changes in dendritic architecture that play a role in hippocampal-dependent learning and memory (Woolley, 1999; Sandstrom and Williams, 2001; Gazzaley et al., 2002).

This increase in spine density involves the formation of new spines and thus requires the synthesis of new proteins within the postsynaptic density (PSD) (Papa and Segal, 1996; Steward and Schuman, 2001). Recent studies have begun to draw attention to the rapid translation of synaptodendritic-localized mRNA transcripts for genes involved in spine formation and function (for review, see Steward, 1997; Gao, 1998; Job and Eberwine, 2001; Richter and Lorenz, 2002). One fundamental structural protein within the PSD is PSD-95, a $95 \mathrm{kDa}$ scaffolding protein containing multiple PSD-95/Discs large/Zona occluens-1 domains to anchor and associate glutamate receptors with other functional pro-

Received Aug. 5, 2002; revised Dec. 13, 2002; accepted Dec. 27, 2002.

This work was supported by National Institutes of Health Grants MH12977 (K.T.A.) and P01AG16765 (B.S.M.), and the Ares-Serono Foundation (K.T.A.).

Correspondence should be addressed to Bruce S. McEwen, Harold and Margaret Milliken Hatch Laboratory of Neuroendocrinology, The Rockefeller University, 1230 York Avenue, Box 165, New York, NY 10021-6399. E-mail: mcewen@rockefeller.edu.

Copyright $\odot 2003$ Society for Neuroscience $\quad 0270-6474 / 03 / 232333-07 \$ 15.00 / 0$ teins in the PSD (Garner et al., 2000; Hering and Sheng, 2001; Sheng, 2001). Another key protein recently localized by electron microscopy (EM) at the PSD of hippocampal pyramidal neurons is estrogen receptor- $\alpha(\mathrm{ER} \alpha)(\mathrm{McEwen}$ et al., 2001; Milner et al., 2001; Adams et al., 2002). By localizing ER $\alpha$ at the PSD, these principal neurons can immediately respond at the synapse to changes in the hormonal environment and provide a means by which estrogen can directly regulate synaptogenesis (Woolley, 1999; Murphy and Andrews, 2000; Brake et al., 2001; Foy, 2001; Yankova et al., 2001).

E can regulate synaptogenesis by both genomic and nongenomic mechanisms (McEwen and Alves, 1999; McEwen et al., 2001). The Akt kinase (Akt, protein kinase B) is an E-responsive signaling intermediate (Ivanova et al., 2002) that is known to participate in regulating protein translation via the rapamycinsensitive mammalian target of rapamycin (mTOR) kinase pathway (Gingras et al., 2001a; Raught et al., 2001). Phosphorylation and consequent activation of Akt result in the downstream hyperphosphorylation of the translational repressor eukaryotic initiation factor (eIF) 4E-binding protein 1 (4E-BP1) (Gingras et al., 1998). This hyperphosphorylation of $4 \mathrm{E}-\mathrm{BP} 1$ relieves its translational repression, and it is a rate-limiting step in translation initiation (Gingras et al., 1999, 2001b). Using the well established in vitro model system of differentiated NG108-15 (dNG108-15) neuroblastoma cells for batch-to-batch consistency and neuronal homogeneity (Hamprecht et al., 1985; Yano et al., 1998), the role of E-activated Akt in PSD-95 protein synthesis was examined. We show here that E treatment of NG108-15 neurons leads to the rapid phosphorylation of Akt and the phosphorylation of $4 \mathrm{E}$ - 
BP1. Also, although $\mathrm{E}$ does not lead to a significant, rapid increase in PSD-95 mRNA levels, it does lead to rapid PSD-95 new protein synthesis.

\section{Materials and Methods}

Cell culture. The NG108-15 neuroblastoma is a hormone-responsive cell line and was purchased at fourth passage from American Type Cell Culture (Manassas, VA; cell line number HB-12317). This cell line is a fusion product from mouse N18TG2 neuroblastoma cells and rat C6-BU-1 glioblastoma cells (Hamprecht, 1977; Hamprecht et al., 1985). These cells are well studied and widely used, and they have already been reported to express several neuronal markers, including neuron-specific enolase, GAP-43, the synaptic marker synaptophysin, and the hippocampalspecific neuronal marker hippocalcin (Grant and Wisden, 1997; Tojima et al., 2000). NG108-15 neurons were routinely propagated from fourth passage in DMEM (Life Technologies, Grand Island, NY) supplemented with $10 \%$ fetal bovine serum (FBS) (Sigma, St. Louis, MO) and $1 \%$ PenStrep (100 U/ml penicillin G sodium and $100 \mu \mathrm{g} / \mathrm{ml}$ streptomycin sulfate; Life Technologies). For differentiation, NG108-15 neurons were plated on poly-L-lysine-coated plates. Poly-L-lysine (Sigma; P6282) was applied at a concentration of $5 \mu \mathrm{g} / \mathrm{ml}$ and allowed to coat plates overnight at $37^{\circ} \mathrm{C}$. Plates were then washed twice with sterile water before use. Two days after plating, the cells were washed twice with Dulbecco's PBS (Life Technologies), and the media was replaced with differentiating medium, consisting of DMEM supplemented with 0.5\% FBS, 1\% PenStrep, and 1 mm dibutyryl cAMP (Sigma; D0627). NG108-15 cells were allowed to differentiate for 7-10 d before any treatment was applied. These dNG108-15 cells demonstrated distinct neuronal morphology of arborized projections that contacted extensions from other neurons and were immunopositive for $\mathrm{ER} \alpha$, as determined by Western blot analysis (data not shown). For E treatment, water-soluble 17 $\beta$-estradiol (Sigma; E4389) was prepared fresh for each independent experiment by dissolving in DMEM at a $10 \mathrm{mM}$ stock concentration $\left(10^{6} \times\right.$ fold stock $)$ and then diluted 1000 times to $10 \mu \mathrm{M}$ in DMEM. Final treatment concentration was then $10 \mathrm{~nm} 17 \beta$-estradiol. For appropriate control treatment, 2 -hydroxypropyl- $\beta$-cyclodextrin ( $\beta$-cyclodextrin) (Sigma; C0926) was also dissolved fresh per experiment in DMEM at a $10^{6} \times$ concentration to the equivalent initial weight to volume ratio $(60.5 \mathrm{mg} / \mathrm{ml})$ as watersoluble $17 \beta$-estradiol. All dilutions and experiments were conducted in phenol red-free DMEM.

Western blotting. For total- and phospho-Akt (pAkt, Ser473) (Cell Signaling Technologies, Beverly, MA; 9272 and 9271, respectively, antibodies purchased under statement to have no cross reactivity) and phospho-4E-BP1 (Thr70) (Cell Signaling Technologies; 9455) Western blot analysis, $5 \times 10^{3}$ NG108-15 cells were plated per well in a poly-Llysine-coated 12-well plate. For time course experiments, neurons were staggered-treated, and all samples were harvested at the same time in $1 \times$ sample buffer. Lysates then were sonified and boiled for $5 \mathrm{~min}$ before separating by SDS-PAGE. An equal volume of prepared lysate was run per condition and transferred to polyvinylidene difluoride membrane (Immobilon-P; Millipore, Bedford, MA). After blocking, the membranes were incubated in primary antibody overnight at $4^{\circ} \mathrm{C}$. HRP-conjugated goat anti-rabbit IgG secondary antibody (Jackson ImmunoResearch, West Grove, PA) was used at a dilution of 1:5000 for $1 \mathrm{hr}$ at room temperature, and visualization was by enhanced chemiluminescence (Renaissance reagent; DuPont NEN, Boston, MA).

Real-time RT-PCR. Total RNA was isolated from control- or $10 \mathrm{nM}$ estrogen-treated dNG108-15 neurons at the indicated time point using RNeasy spin columns (Qiagen, Valencia, CA). First-strand cDNA was prepared by RT from equal amounts of total RNA per sample $(5 \mu \mathrm{g})$ using oligo-dT primer and SuperScript II reverse transcriptase (Life Technologies). Real-time PCR was subsequently performed on RT from samples to quantitatively determine the relative amounts of gene-specific cDNAs. For PSD-95, the following primers were used: [PSD95-forward (-FOR) 5'-CGA GGA TGC CGT GGC AGC C-3' and PSD95-reverse (-REV) 5'-CAT GGC TGT GGG GTA GTC AGT GCC-3'. For $\delta$-opioid receptor $(\delta \mathrm{OR})$ (which was also measured to normalize total RNA per sample), the following primers were used: ( $\delta \mathrm{OR}-\mathrm{FOR}) 5^{\prime}$-GCG CCT
TCG TGG TGT GCT GG-3' and (8OR-REV) 5'-GTA GCC CAG CGC AAT GCA CAG G-3'. PCR was with SYBR-green PCR Master Mix and AmpliTaq Gold DNA Polymerase (Applied Biosystems, Foster City, CA) and was run on a 7000 ThermoCycler (Applied Biosystems). Per sample, the amount of PSD-95 cDNA was first normalized by the amount of $\delta \mathrm{OR}$ cDNA, and then this normalized level of PSD-95 cDNA from estrogentreated sample was expressed as a fold increase relative to the normalized level from control-treated sample. Data presented are the average and SD from three independent experiments performed in triplicate and expressed as fold increase over control.

Metabolic labeling and immunoprecipitation. Differentiated NG108-15 neurons grown on precoated $10 \mathrm{~cm}$ tissue culture dishes were depleted of methionine (Met) and cystine (Cys) for $24 \mathrm{hr}$ by washing off cells once with D-PBS and then replacing the medium with Met-free and Cys-free DMEM (Life Technologies) and 0.5\% dialyzed Met-free and Cys-free FBS (Life Technologies). $\left[{ }^{35} \mathrm{~S}\right]$-methionine/cystine metabolic labeling $\operatorname{mix}$ (DuPont NEN; NEG-772) at a final concentration of $100 \mu \mathrm{Ci} / \mathrm{ml}$ was supplemented to and maintained in this labeling medium. The dNG108-15 neurons then were staggered-treated for indicated time periods with either a final concentration of $10 \mathrm{~nm} 17 \beta$-estradiol or an equivalent amount of $\beta$-cyclodextrin control, and all samples were collected at the same time. To prepare and collect labeled lysates, the labeling medium was removed, and the cells were washed once with prewarmed Met-free/Cys-free DMEM. Ice-cold RIPA buffer ( $1 \times$ D-PBS, $1 \%$ NP-40, $0.5 \%$ sodium deoxycholate, $0.1 \%$ SDS) with fresh protease and phosphatase inhibitors was added to each plate, and the cells were allowed to lyse at $4^{\circ} \mathrm{C}$ for $10 \mathrm{~min}$ with gentle rocking. Lysates then were scrape-collected into Eppendorf tubes and precleared by incubating with agaroseconjugated normal mouse IgM (50\% slurry; Santa Cruz Biotechology, Santa Cruz, CA). PSD-95 protein was immunoprecipitated overnight at $4^{\circ} \mathrm{C}$ with $1 \mu \mathrm{g}$ of mouse monoclonal anti-PSD-95 antibody (Upstate Biotechnology, Lake Placid, NY) and then collected with Protein G-PLUS agarose (Santa Cruz Biotechology). The immunoprecipitate was washed stringently four times with RIPA buffer and fresh protease and phosphatase inhibitors, and the complex was then pelleted for resuspension in SDS sample buffer supplemented with $1 \% \beta$-mercaptoethanol. The samples were boiled for $5 \mathrm{~min}$ and then separated by SDSPAGE, and the gels were dried overnight and exposed to a PhosphorImaging screen (Molecular Dynamics, Sunnyvale, CA). Visualization and phosphor-densitometry was performed by ImageQuant version 1.2 software (Molecular Dynamics). Collectively, immunoprecipitation controls include an equal number of cells plated per well and equal amounts of quantitated total protein lysates per sample incubated with equal amounts of antibody. Data presented are averages and SD from three independent experiments.

Signal transduction inhibitors. For inhibitor preincubation, metabolically $\left[{ }^{35} \mathrm{~S}\right.$ ]-labeled dNG108-15 neurons were prepared as above. Identical volumes of various inhibitors or an equal volume of diluent DMSO control was immediately provided in the metabolic labeling medium, and the cells were preincubated for $1 \mathrm{hr}$ at $37^{\circ} \mathrm{C}$ before $6 \mathrm{hr}$ control or 10 nм $17 \beta$-estradiol treatment. The selective ER $\alpha$ antagonist ICI 182,780 (Tocris, Ballwin, MO) was used at a final concentration of $100 \mathrm{~nm}$, or 10 -fold greater concentration over $17 \beta$-estradiol. To inhibit Akt activation, the phosphatidyl-inositol 3-kinase (PI3K) inhibitor LY294002 (Cell Signaling Technologies) was used at a final concentration of $50 \mu \mathrm{M}$. To inhibit mTOR kinase, $10 \mathrm{~nm}$ rapamycin (Cell Signaling Technologies) was used. To inhibit RNA transcription, $4 \mu \mathrm{M}$ actinomycin D (Sigma) was used. ${ }^{35} \mathrm{~S}$-metabolically labeled cells were harvested, and the lysates were analyzed as above.

Statistical analysis. All of the numerical data are presented as average \pm $\mathrm{SD}$ from at least three independent experiments. Statistical significance was calculated using Student's two-tailed $t$ test (paired two-sample for means) to determine whether compared groups are distinct. Significant distinction between compared groups was noted if $p<0.05$. If $p>0.05$, compared groups were considered to be indistinct with no significant difference between them. 


\section{Results}

\section{Estrogen and Akt phosphorylation}

E treatment of primary cortical neurons is known to lead to Akt phosphorylation, an indication of Akt kinase activation. Differentiated NG108-15 neurons were treated with either $10 \mathrm{~nm} 17 \beta$ estradiol or $60.5 \mathrm{ng} / \mathrm{ml} \beta$-cyclodextrin (control), and a time course was established to determine the effects on Akt phosphorylation. Whole-cell lysates were prepared from neurons treated for indicated times, and Western blots were analyzed for either Ser-473-phosphorylated Akt (Fig. $1 A, p A k t$ ) or total Akt (Fig. $1 B$, $A k t)$. Although control-treatment did not lead to a significant increase in pAkt levels when compared with the pAkt level in untreated dNG108-15 neurons (used as $0 \mathrm{hr}$ time point), E treatment led to a robust increase of pAkt levels in dNG108-15 neurons as rapidly as $30 \mathrm{~min}$, which was maintained throughout $4 \mathrm{hr}$. Levels of total Akt protein remained unchanged throughout the time course in both control- and E-treated samples. As a positive control for Akt phosphorylation, prepared lysate from $100 \mathrm{~nm}$ insulin-treated (1 hr) dNG108-15 neurons was run alongside each experiment. Semiquantitative densitometric analyses of Western blots indicate that by $4 \mathrm{hr}$, E treatment of dNG108-15 neurons leads to a fourfold increase in pAkt (Ser473) levels over control treatment (Fig. 1C).

\section{Estrogen stimulates the phosphorylation of 4E-BP1}

These same whole-cell lysates with consistent levels of total Akt protein per sample that were used in establishing a time course of E-stimulated Akt phosphorylation then were further used to determine a time course of 4E-BP1 (Thr70) phosphorylation. 4EBP1 normally binds to eIF4E, thereby inhibiting cap-dependent protein translation (Gingras et al., 1999). Activation of the PI3K/ Akt pathway can lead to the hyperphosphorylation of $4 \mathrm{E}-\mathrm{BP} 1$, which consequently disrupts its binding capabilities, thereby activating cap-dependent protein translation (Gingras et al., 1998). Recently, 4E-BP1 has been immunolocalized to dendritic spines in primary cultured hippocampal neurons (Tang et al., 2002), indicating that in the hippocampus, this regulatory protein may have a role in activity-dependent local protein synthesis at the synapse.

Similar to Akt phosphorylation, control treatment of dNG108-15 neurons did not lead to an increase in phosphorylated 4E-BP1 (p4E-BP1) levels (Fig. 2A, lanes 2-7). However, E treatment of dNG108-15 neurons led to an increase in p4E-BP1 levels by $1 \mathrm{hr}$, and this phosphorylation steadily increased throughout $4 \mathrm{hr}$ of $\mathrm{E}$ treatment (Fig. 2A, lanes 8-12). Semiquantitative densitometric analysis of each experiment indicates that significant increases in p4E-BP1 levels occurred after $1 \mathrm{hr}$ of E treatment and continued throughout $4 \mathrm{hr}$, increasing $>12$-fold over control (Fig. 2B). Time course analysis of $\mathrm{p} 4 \mathrm{E}-\mathrm{BP} 1$ indicates that $4 \mathrm{E}-\mathrm{BP} 1$ phosphorylation generally follows Akt phosphorylation.

These Western blot analyses indicate that E treatment of dNG108-15 neurons leads to the phosphorylation of Akt and subsequent phosphorylation of $4 \mathrm{E}-\mathrm{BP} 1$ and suggest that $\mathrm{E}$ may have a non-genomic role in regulating neuronal gene expression at the level of protein translation.

\section{Estrogen and PSD-95 mRNA levels}

Because new spine formation requires the putative production of new spine-specific proteins, the effects of E on PSD-95 gene expression were pursued. Total RNA was isolated from $6 \mathrm{hr}$ control-treated and $6 \mathrm{hr}$ E-treated dNG108-15 neurons, and PSD-95 mRNA levels were determined by quantitative real-time

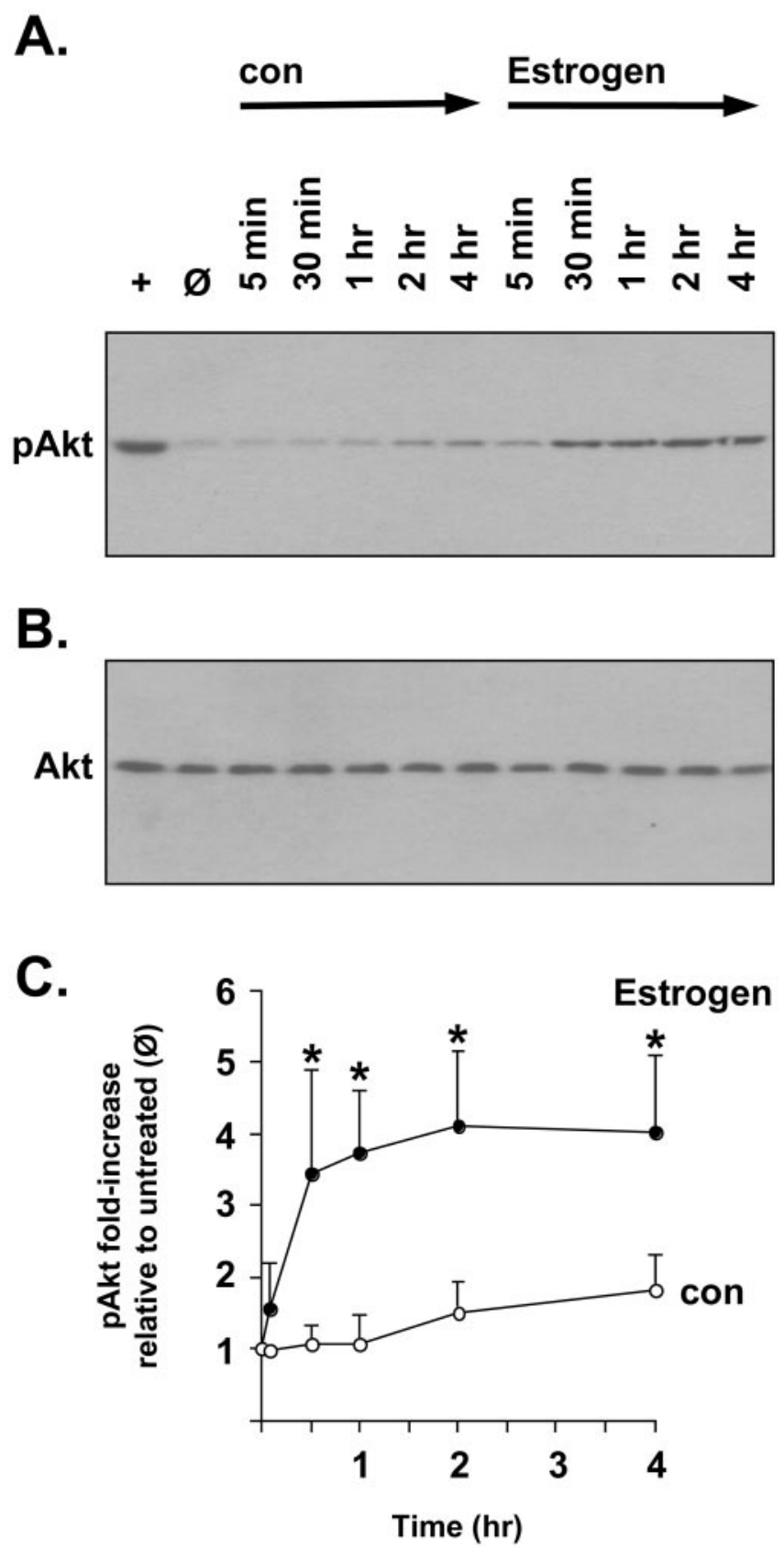

Figure 1. Estrogen rapidly stimulates the phosphorylation of Akt. dNG108-15 neurons were treated with either control (con) ( $\beta$-cyclodextrin) or $10 \mathrm{~nm} 17 \beta$-estradiol (Estrogen) for the times indicated. + indicates positive control treatment of dNG108-15 neurons, 60 min exposure to $100 \mathrm{~nm}$ insulin. $\varnothing$ indicates untreated dNG108-15 neurons. Phosphorylated Akt ( $p A k t$ ) at Ser-473 $(A)$ or total Akt (non-phosphospecific) ( $B$ ) was measured by Western blot analysis of total cell lysates of cells solubilized in SDS loading buffer and run on 10\% SDS-PAGE. C, Semiquantitative densitometry of scanned blots. pAkt levels were first normalized to total Akt levels, and then each normalized pAkt level was expressed as fold increase over pAkt level from untreated $(\emptyset)$ cells. As early as $30 \mathrm{~min}$, estrogen treatment rapidly stimulates an approximate fourfold increase in pAkt levels over control treatment. Graphed data represent averages and SD from three independent experiments. * Statistically significant over control from same time point ( $p<0.05$; two-tailed Student's $t$ test).

RT-PCR. To normalize for starting material template, the singlecopy gene (Bzdega et al., 1993) for the $\delta$ OR was simultaneously measured for each sample. After $6 \mathrm{hr}$ of $10 \mathrm{nM} 17 \beta$-estradiol treatment, there was no significant change in PSD-95 mRNA levels relative to control treatment (Figs. 3, 4) (two-tailed Stu- 


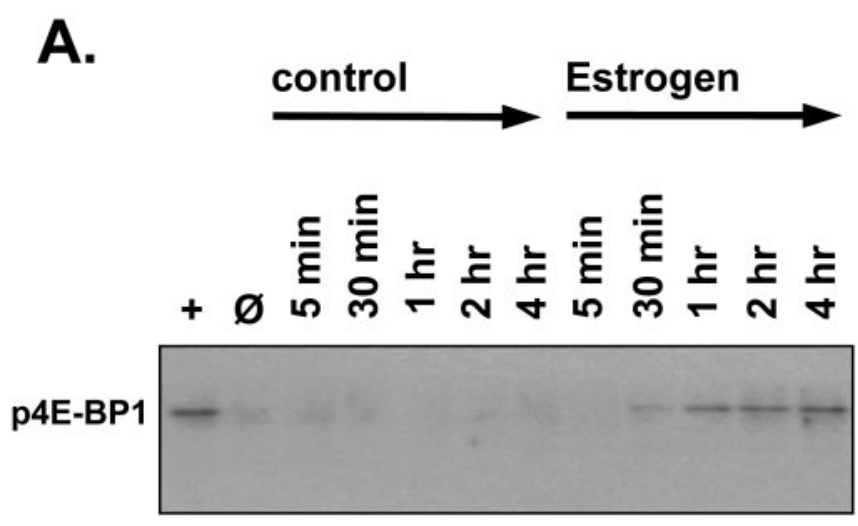

B.

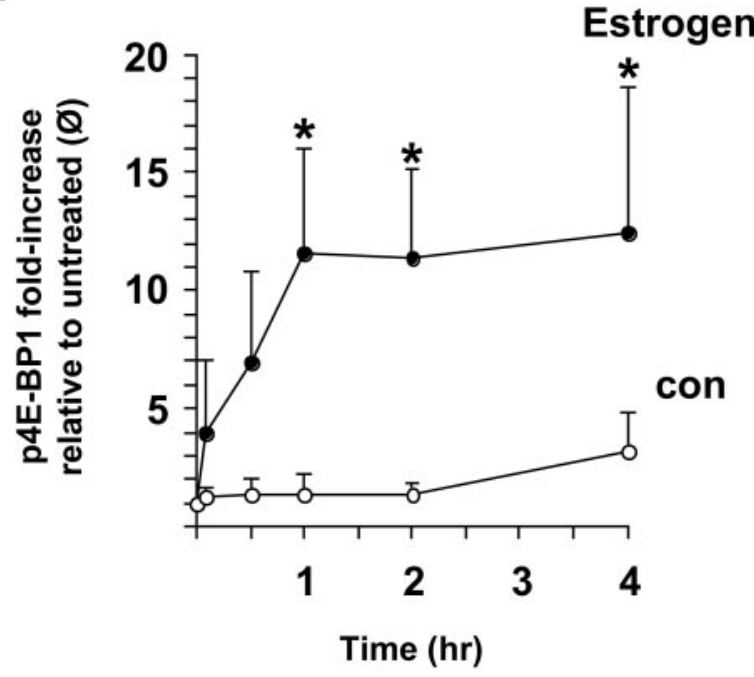

Figure 2. Estrogen stimulates the phosphorylation of $4 E-B P 1$. The same lysates from Figure 1 were analyzed for phosphorylation of 4E-BP1 ( $p 4 E-B P 1$ ) at Thr70 by Western blot analysis. $A$, Samples were run on $15 \%$ SDS-PAGE, and the blot shown is representative of three independent experiments. Control treatment did not lead to 4E-BP1 phosphorylation, but $10 \mathrm{~nm} 17 \beta$ estradiol treatment lead to an increase in p4E-BP1 that increased steadily through $4 \mathrm{hr} . B$, Semiquantitative densitometric analysis of p4E-BP1 levels.

dent's $t$ test; $p>0.05)$. E therefore does not appear to affect the levels of PSD-95 mRNA in dNG108-15 neurons after only $6 \mathrm{hr}$ of treatment. It is significant to note, however, that even in mRNA isolated from control-treated dNG108-15 neurons, PSD-95 mRNA can be detected by RT-PCR. PSD-95 mRNA can also be detected by RT-PCR in untreated dNG108-15 neurons (data not shown). This demonstrates that although $\mathrm{E}$ treatment does not change the levels of PSD-95 mRNA, PSD-95 mRNA is still present in dNG108-15 neurons.

Estrogen stimulates PSD-95 new protein synthesis

Because E did not significantly affect the levels of PSD-95 mRNA transcription, the next level of gene expression to consider therefore was protein translation and the regulated synthesis of new PSD-95 protein. Because E treatment can rapidly stimulate the Akt signal transduction pathway and leads to the subsequent phosphorylation of $4 \mathrm{E}-\mathrm{BP} 1$, we examined the effects of $\mathrm{E}$ on new protein synthesis by $\left[{ }^{35} \mathrm{~S}\right]$-metabolically pulse labeling dNG108-15 neurons at the start of treatment. Only newly syn-

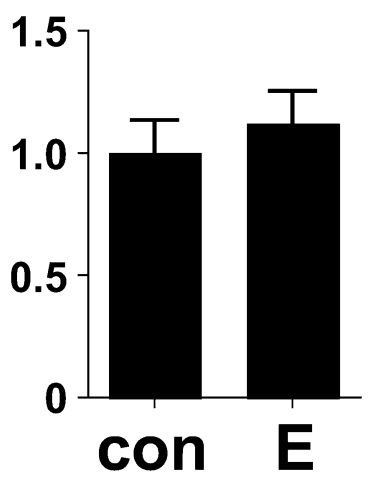

Figure 3. Estrogen does not affect PSD-95 mRNA levels. Equal amounts of total RNA isolated from control-treated (con) and $10 \mathrm{~nm} 17 \beta$-estradiol-treated $(E) \mathrm{dNG} 108$-15 neurons were analyzed by real-time RT-PCR to quantitate the amount of PSD-95 mRNA. The mRNA level from the single-copy $\partial$-opioid receptor gene was also measured to normalize for total RNA per sample. Data represent averages and SD from three independent experiments, each run in triplicate, and are expressed as fold increase over control-treated sample. After 6 hr estrogen treatment, there is no significant change in PSD-95 mRNA levels (Student's two-tailed $t$ test; $p>0.05$ )

thesized proteins would incorporate the isotopic label, and so new protein synthesis can be quantitated by phosphorimage densitometry. [ $\left.{ }^{35} \mathrm{~S}\right]$-labeled dNG108-15 neurons were treated initially with $10 \mathrm{~nm} 17 \beta$-estradiol or control for various lengths of time, and a general upregulation of $\left[{ }^{35} \mathrm{~S}\right]$ incorporation was evident in SDS-PAGE separated whole-cell protein extracts as early as $4 \mathrm{hr}$ after E treatment versus control (data not shown). Therefore, to look specifically at PSD-95 new protein synthesis, $\left[{ }^{35} \mathrm{~S}\right]$-labeled PSD-95 was isolated by immunoprecipitation (ip), and the PSD-95 ip was analyzed by SDS-PAGE. To identify any signaling intermediates that may participate in such PSD-95 new protein synthesis, $1 \mathrm{hr}$ before $\mathrm{E}$ treatment dNG108-15 neurons were first metabolically labeled and simultaneously preincubated with different pharmacologic inhibitors to selectively block various signal transduction pathways. The following inhibitors or inhibitor diluent controls were used for inhibitor preincubation: (1) the selective $\mathrm{ER} \alpha$ antagonist ICI 182,780; (2) the PI3K inhibitor LY294002, which prevents PI3K-dependent Akt activation; (3) the mTOR kinase inhibitor rapamycin, which leads to the dephosphorylation of 4E-BP1 and thereby maintains repression on eIF4E-dependent protein synthesis; and (4) actinomycin D, a potent inhibitor of RNA transcription. After $1 \mathrm{hr}$ of inhibitor preincubation with these inhibitors, dNG108-15 neurons were treated for $6 \mathrm{hr}$ with either control or E, and PSD-95 was then immunoprecipitated from isolated whole-cell extracts (Fig. 4A, PSD-95 ip).

New PSD-95 protein synthesis was determined by phosphorimage densitometry on $\left[{ }^{35} \mathrm{~S}\right]$-labeled PSD-95 ip (Fig. $4 \mathrm{~B}$ ) to measure changes in protein synthesis after E treatment. In the absence of any inhibitors, E rapidly stimulated an approximate threefold increase in the synthesis of new PSD-95 protein (Fig. 4B, lane 2). When dNG108-15 neurons were preincubated with actinomycin $\mathrm{D}$ to inhibit RNA transcription, there was a slight decrease in PSD-95 new protein synthesis, but this decrease is not statistically significant from E treatment alone (Fig. $4 B$, lane 2 vs 6 ) (twotailed Student's $t$ test; $p>0.05$ ). This would indicate that most of the metabolically labeled new PSD-95 protein was translated at this time point from mRNA already present. Both $\mathrm{ER} \alpha$ antagonist and PI3K inhibitors reduced E-stimulated PSD-95 protein synthesis to near control-stimulated levels (Fig. 4 B, lanes 3 and 4 vs lane 1), and mTOR inhibitor preincubation reduced E-stimulated PSD-95 new 


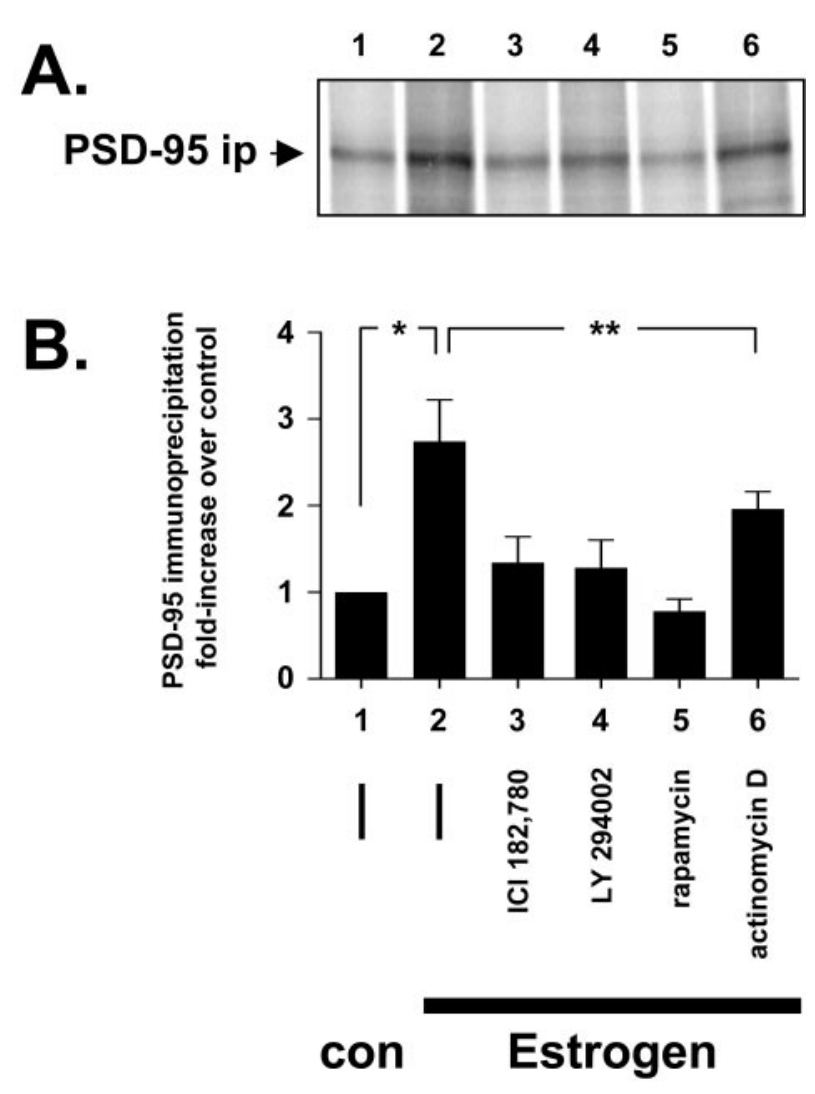

Figure 4. PSD-95 new protein synthesis. Metabolically $\left[{ }^{35} S\right.$-Met/Cys] pulse-labeled dNG108-15 neurons were preincubated for $1 \mathrm{hr}$ with either inhibitor (lane 3, $100 \mathrm{~nm} \mathrm{ICI} \mathrm{182,780;}$ lane 4,50 $\mu \mathrm{m}$ LY294002; lane 5, 10 nm rapamycin; lane 6, $4 \mu$ m actinomycin D) or (一) inhibitor diluent control (equivalent volume DMSO, lanes 1 and 2). Then, the neurons were either treated for an additional $6 \mathrm{hr}$ with $\beta$-cyclodextrin control (con, lane 1) or $10 \mathrm{~nm} 17 \beta$-estradiol (Estrogen, lanes 2-6). The cells were harvested in ice-cold RIPA buffer, and the cleared extract was immunoprecipitated for PSD-95 protein. After stringent washing, the immunoprecipitate was run by $7.5 \%$ SDS-PAGE, and the dried acrylamide gel was then exposed to a phosphorimage screen for densitometry. Only newly synthesized PSD-95 protein with [ $\left.{ }^{35} \mathrm{~S}\right]$ incorporation is captured by the phosphorimaging screen. $A$, The PSD-95 immunoprecipitation (PSD-95 ip); $B$, the corresponding densitometry analysis. In the absence of inhibitors, estrogen stimulates an approximate threefold increase in new PSD-95 protein synthesis (significantly greater than control; Student's two-tailed $t$ test; ${ }^{*} p<0.05$ ). This protein synthesis is reduced to near control levels (lane 1) by either the ER $\alpha$ antagonist ICI 182,780 (lane 3) or the PI3K inhibitor LY294002 (Iane 3). Rapamycin is a potent mTOR kinase inhibitor and can inhibit protein synthesis, and it reduces estrogen-stimulated PSD-95 protein synthesis to below control levels (lane 5). Actinomycin D inhibits mRNA transcription and decreases slightly estrogen-stimulated PSD-95 new protein synthesis (lane 6). However, this decrease is not statistically significant (Student's two-tailed $t$ test; ${ }^{* *} p>0.05$ ) and suggests that PSD-95 protein synthesis is transcription independent.

protein synthesis to below control-stimulated levels (Fig. 4B, lane 5 vs lane 1).

Collectively, these data indicate that the rapid E stimulation of PSD-95 new protein synthesis in dNG108-15 neurons is ER $\alpha$, Akt, and mTOR dependent, but RNA transcription independent, and is diagrammed schematically in Figure 5.

\section{Discussion}

Non-genomic actions of estrogen in neurons

It is well established that $\mathrm{E}$ regulates synaptogenesis in the CA1 region of the dorsal hippocampus during the estrous cycle (Woolley, 1999; Yankova et al., 2001). At proestrus, when circulating estrogens are at highest concentration, there is a significant increase in dendritic spine density in CA1 principal neurons, and exogenous administration of $\mathrm{E}$ to ovariectomized female rats in vivo or to primary cultured neurons in vitro leads to an increase in

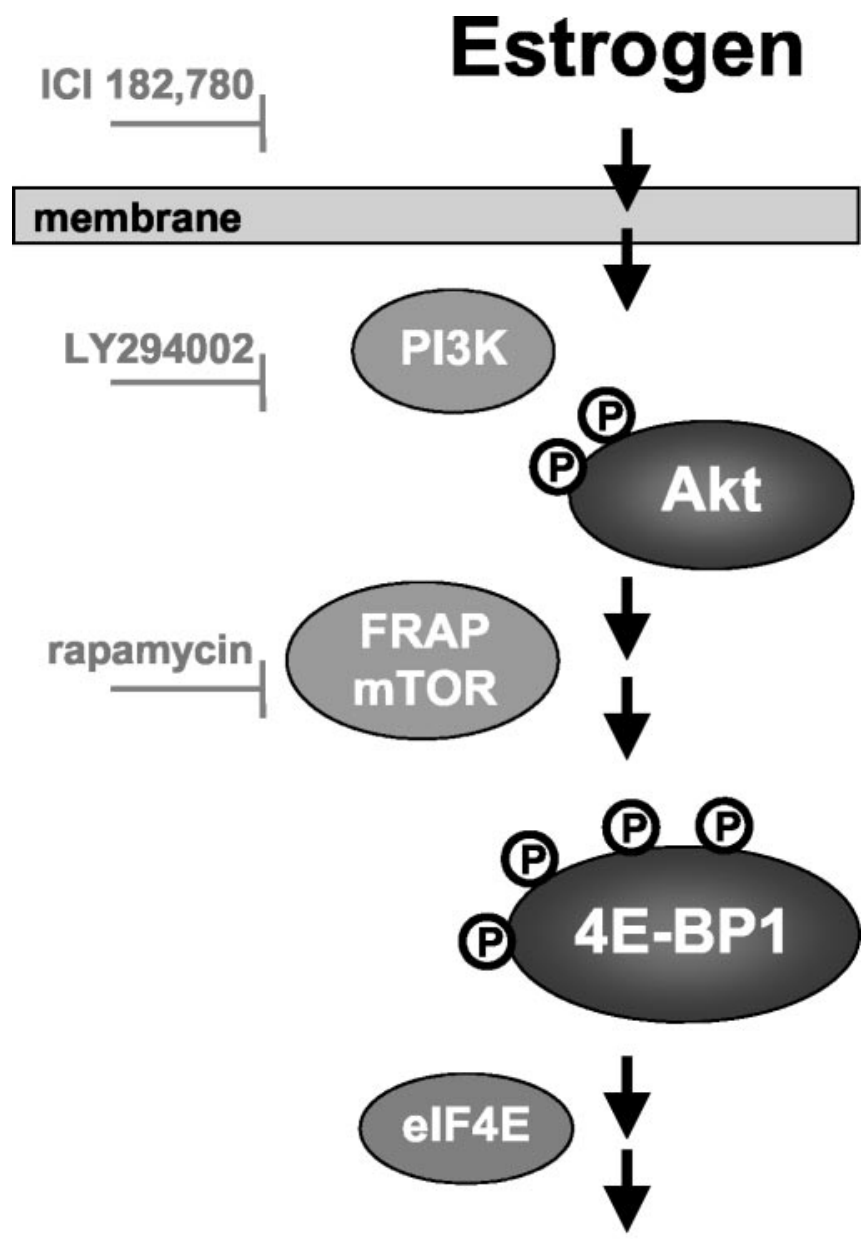

\section{PSD-95 Protein Translation}

Figure 5. Model of estrogen action on PSD-95 new protein synthesis. Estrogen stimulates rapid PSD-95 new protein synthesis via Akt and 4E-BP1 phosphorylation. This signal transduction pathway leading to PSD-95 protein translation can be inhibited by the ER $\alpha$ antagonist ICI 182,780, by the PI3K selective inhibitor LY294002, and by the mTOR kinase inhibitor rapamycin. FRAP, FKBP (FK506-binding protein) and rapamycin-associated protein.

spine density. The functional consequences of such E-stimulated increases in spine density include enhancement of long-term potentiation (LTP) sensitivity as well as performance improvement in learning and memory tasks (for review, see McEwen et al., 2001). With the recent localization by electron microscopy of $\mathrm{ER} \alpha$ to the dendritic spines and dendritic shafts in hippocampal neurons (Milner et al., 2001; Adams et al., 2002), we can now begin to delineate the molecular mechanisms by which $\mathrm{E}$ might directly orchestrate such spine formation and synaptogenesis.

This study therefore addresses these non-genomic actions of $\mathrm{E}$ in neurons and how they relate to new protein synthesis and new spine formation. We demonstrate here that $\mathrm{E}$ treatment of a differentiated neuronal cell line can lead to the (1) rapid phosphorylation of the signal transduction intermediate Akt and (2) subsequent phosphorylation of 4E-BP1. We also demonstrate that $\mathrm{E}$ can stimulate the translation of the dendritic spine scaffolding protein PSD-95 in (3) an Akt-dependent and (4) a transcriptionindependent manner.

E can stimulate the phosphorylation of Akt via PI3K in vitro in both neuronal and non-neuronal cells. One way E may be coupled to Akt is at the cell membrane, where PI3K is able to associate 
directly with ER $\alpha$ (Simoncini et al., 2000). We have verified this estrogenic effect on Akt phosphorylation in these differentiated neurons and expand on this finding by demonstrating for the first time that $\mathrm{E}$ further leads to the phosphorylation of the Akt downstream target 4E-BP1. Activation of Akt can lead to the hyperphosphorylation of 4E-BP1, either via mTOR kinase or by p70 76 kinase (Gingras et al., 2001a), both of which are inhibited by rapamycin. Hyperphosphorylation of 4E-BP1 alleviates its translational repression, and this hyperphosphorylation is a ratelimiting step in the regulation of new protein synthesis. Recently, $4 \mathrm{E}-\mathrm{BP} 1$ has been immunolocalized to dendritic spines of cultured primary hippocampal neurons in vitro (Tang et al., 2002), thereby potentially positioning 4E-BP1 to regulate synaptic activity-dependent protein synthesis. Together, with our findings that $\mathrm{ER} \alpha$ immunoreactivity also is present in dendritic spines in vivo (Milner et al., 2001), our data demonstrating that $\mathrm{E}$ can stimulate $4 \mathrm{E}-\mathrm{BP} 1$ phosphorylation suggests that estrogen is a likely key effector of spine formation and synaptogenesis via regulating spine-specific local protein synthesis.

\section{Estrogen primarily regulates $\mathrm{PSD}-95$ protein expression at the translational level}

To date, there is no evidence that $\mathrm{E}$ increases PSD-95 gene expression or protein levels in vivo. Moreover, because PSD-95 studies on spine function are relatively recent, no studies have characterized PSD-95 regulation in vivo or in vitro. Two in vivo studies had begun to look at developmental expression patterns in cortical and hippocampal areas by Western blot analysis (Sans et al., 2000) and in situ hybridization (Fukaya et al., 1999). To date, all in vitro studies, so far by transient transfection of overexpression constructs, have focused on how PSD-95 expression can drive spine function and spine maturation (El-Husseini et al., 2000) but not on how PSD-95 is itself regulated. Because there are no signal transduction pathways yet known to be involved in PSD-95 expression, this study is the first study to address specific mechanisms regulating the endogenous levels of PSD-95 protein.

Actinomycin D pretreatment was used to inhibit mRNA transcription. Although not statistically significant, addition of this inhibitor resulted in a minor decrease in PSD-95 new protein synthesis, indicating that some, although negligible, PSD-95 protein synthesis is mRNA transcription dependent. Indeed, when extended time points were examined, some new PSD-95 mRNA synthesis began to participate in subsequent new protein synthesis (our unpublished observations). Therefore, in the present study, E stimulation was restricted to only $6 \mathrm{hr}$ to demonstrate that the observed, rapid new PSD-95 protein synthesis is not dependent on mRNA transcription but rather on the existing population of PSD-95 mRNA already transcribed. To produce such a rapid effect, it would be necessary for $\mathrm{E}$ to function via non-genomic mechanisms and directly on the neurons, without the participation of any intermediate cellular or gene expression assistance. Although alternative signal transduction pathways may later participate in a slower, genomic response in E-stimulated PSD-95 gene expression, this E-stimulated, rapid PSD-95 new protein synthesis observed at 6 $\mathrm{hr}$ appears to be a direct, non-genomic result.

\section{Estrogen and localized protein synthesis}

The regulation of protein synthesis at the dendritic spine from prelocalized mRNA transcripts independent of the neuronal cell body is an emerging field of hippocampal synaptic plasticity and LTP (for review, see Gardiol et al., 1999; Job and Eberwine, 2001; Richter and Lorenz, 2002). Recently, LTP has been shown to be protein synthesis dependent (Tang et al., 2002). Transcripts of genes involved in spine formation and function are currently being isolated and identified from the synaptodendritic compartment of neurons (Tian et al., 1999; Eberwine et al., 2001). Furthermore, cellular protein translation machinery including ribosomes has been identified near the dendritic spine in vivo (Steward and Falk, 1991; Gardiol et al., 1999; Krichevsky and Kosik, 2001). Because these findings describe a role for local protein synthesis in hippocampal synaptic function, it has yet to be determined whether upstream signaling intermediates such as Akt, a kinase that can activate protein translation, are also found at or near the dendritic spine in vivo.

Although protein translation may be concurrently activated within the neuronal cell body, E may mediate Akt-dependent protein translation of spine-specific proteins such as PSD-95. In support of this assertion, we have found, by using electron microscopy, a cyclic redistribution of pAkt in hippocampal CA1 dendritic spines over the estrous cycle, peaking at proestrus [see companion article in this issue (Znamensky et al., 2003)]. This study suggests that increasing levels of circulating ovarian hormone increase the levels of activated Akt specifically at the dendritic spine in vivo and supports the non-genomic role of $\mathrm{E}$ in regulating localized protein synthesis. Because selective signal transduction inhibitors were able to abrogate such E-stimulated new PSD-95 protein synthesis in vitro, we can delineate a molecular pathway by which $\mathrm{E}$ may regulate dendritic spine formation in the hippocampus in vivo.

Current directions from the present study extend investigations into E-mediated PSD-95 gene expression. In the hippocampus, PSD-95 expression in vivo is not limited to dendritic spines of principal neurons, but it is also expressed in citron-positive interneurons (Zhang et al., 1999). Because of this cell type heterogeneity of PSD-95 expression, the subtle effects of $E$ on principal neurons are masked when analyzed by light microscopy (LM). To overcome the inadequacy of LM analysis, we have begun to study E-stimulated PSD-95 expression further at the ultrastructural level of the dendritic spine by EM.

These findings from the present study together with the findings in the companion article (Znamensky et al., 2003) collectively suggest that, in addition to genomic mechanisms initiated within the nucleus, another novel mechanism by which $\mathrm{E}$ can stimulate the formation of new spines is by the non-genomic regulation of specific signal transduction pathways such as Akt and $4 \mathrm{E}-\mathrm{BP} 1$ that participate and converge in the translation of new proteins from previously localized mRNA transcripts independent of stimulated gene expression.

\section{References}

Adams MM, Fink SE, Shah RA, Janssen WGM, Hayashi S, Milner TA, McEwen BS, Morrison JH (2002) Estrogen and aging affect the subcellular distribution of estrogen receptor- $\alpha$ in the hippocampus of female rats. J Neurosci 22:3608-3614.

Brake WG, Alves SE, Dunlop JC, Lee SJ, Bulloch K, Allen PB, Greengard P, McEwen BS (2001) Novel target sites for estrogen action in the dorsal hippocampus: an examination of synaptic proteins. Endocrinology 142:1284-1289.

Bzdega T, Chin H, Kim H, Jung HH, Kozak CA, Klee WA (1993) Regional expression and chromosomal localization of the $\partial$-opiate receptor gene. Proc Natl Acad Sci USA 90:9305-9309.

Eberwine J, Miyashiro K, Kacharmina JE, Job C (2001) Local translation of classes of mRNAs that are targeted to neuronal dendrites. Proc Natl Acad Sci USA 98:7080-7085

El-Husseini AE, Schnell E, Chetkovich DM, Nicoll RA, Bredt DS (2000) PSD-95 involvement in maturation of excitatory synapses. Science 290:1364-1368.

Foy MR (2001) 17 $\beta$-estradiol: effect on CA1 hippocampal synaptic plasticity. Neurobiol Learn Mem 76:239-252. 
Fukaya M, Ueda H, Yamauchi K, Inoue Y, Watanabe M (1999) Distinct spatiotemporal expression of mRNAs for the PSD-95/SAP90 protein family in the mouse brain. Neurosci Res 33:111-118.

Gao FB (1998) Messenger RNAs in dendrites: localization, stability, and implications for neuronal function. BioEssays 20:70-78.

Gardiol A, Racca C, Triller A (1999) Dendritic and postsynaptic protein synthetic machinery. J Neurosci 19:168-179.

Garner CC, Nash J, Huganir RL (2000) PDZ domains in synapse assembly and signaling. Trends Cell Biol 10:274-280.

Gazzaley A, Kay S, Benson DL (2002) Dendritic spine plasticity in hippocampus. Neurosci. 111:853-862.

Gingras AC, Kennedy SG, O’Leary MA, Sonenberg N, Hay N (1998) 4E$\mathrm{BP} 1$, a repressor of mRNA translation, is phosphorylated and inactivated by the Akt(PKB) signaling pathway. Genes Dev 12:502-513.

Gingras AC, Raught B, Sonenberg N (1999) eIF4 initiation factors: effectors of mRNA recruitment to ribosomes and regulators of translation. Annu Rev Biochem 68:913-963.

Gingras AC, Raught B, Sonenberg N (2001a) Regulation of translation initiation by FRAP/mTOR. Genes Dev 15:807-826.

Gingras AC, Raught B, Gygi SP, Niedzwiecka A, Miron M, Burley SK, Polakiewicz RD, Wyslouch-Cieszynska A, Aebersold R, Sonenberg N (2001b) Hierarchical phosphorylation of the translation inhibitor 4E-BP1. Genes Dev 15:2852-2864.

Gould E, Woolley CS, Frankfurt M, McEwen BS (1990) Gonadal steroids regulate dendritic spine density in hippocampal pyramidal cells in adulthood. J Neurosci 10:1286-1291.

Grant AL, Wisden W (1997) DNA regions supporting hippocalcin gene expression in cell lines. Mol Brain Res 52:323-325.

Hamprecht B (1977) Structural, electrophysiological, biochemical, and pharmacological properties of neuroblastoma-glioma cell hybrids in cell culture. Int Rev Cytol 49:99-170.

Hamprecht B, Glaser T, Reiser G, Bayer E, Propst F (1985) Culture and characteristics of hormone-responsive neuroblastoma $\mathrm{x}$ glioma hybrid cells. Methods Enzymol 109:316-341.

Hering H, Sheng M (2001) Dendritic spines: structure, dynamics and regulation. Nat Rev Neurosci 2:880-888.

Ivanova T, Mendez P, Garcia-Segura LM, Beyer C (2002) Rapid stimulation of the PI3-kinase/Akt signaling pathway in developing midbrain neurones by oestrogen. J Neuroendocrinol 14:73-79.

Job C, Eberwine J (2001) Localization and translation of mRNA in dendrites and axons. Nat Rev Neurosci 2:889-898.

Krichevsky AM, Kosik KS (2001) Neuronal RNA granules: a link between RNA localization and stimulation-dependent translation. Neuron 32:683-696.

McEwen BS, Alves SE (1999) Estrogen actions in the central nervous system. Endocr Rev 20:279-307.

McEwen BS, Akama KT, Alves SE, Brake WG, Bulloch K, Lee SJ, Li CJ, Yuen GS, Milner TA (2001) Tracking the estrogen receptor in neurons: implications for estrogen-induced synapse formation. Proc Natl Acad Sci USA 98:7093-7100.

Milner TA, McEwen BS, Hayashi S, Li CJ, Reagan LP, Alves SE (2001) Ultrastructural evidence that hippocampal alpha estrogen receptors are located at extranuclear sites. J Comp Neurol 429:355-371.
Murphy DD, Andrews SB (2000) Culture models for the study of estradiolinduced synaptic plasticity. J Neurocytol 29:411-417.

Papa M, Segal M (1996) Morphological plasticity in dendritic spines of cultured hippocampal neurons. Neuroscience 71:1005-1011.

Raught B, Gingras AC, Sonenberg N (2001) The target of rapamycin (TOR) proteins. Proc Natl Acad Sci USA 98:7037-7044.

Richter JD, Lorenz LJ (2002) Selective translation of mRNAs at synapses. Curr Opin Neurobiol 12:300-304.

Sandstrom NJ, Williams CL (2001) Memory retention is modulated by acute estradiol and progesterone replacement. Behav Neurosci 115:384-393.

Sans N, Petralia RS, Wang Y-X, Blahos IIJ, Hell JW, Wenthold RJ (2000) A developmental change in NMDA receptor-associated proteins at hippocampal synapses. J Neurosci 20:1260-1271.

Sheng M (2001) Molecular organization of the postsynaptic specialization. Proc Natl Acad Sci USA 98:7058-7061.

Simoncini T, Hafezi-Moghadam A, Brazil DP, Ley K, Chin WW, Liao JK (2000) Interaction of oestrogen receptor with the regulatory subunit of phosphatidylinositol-3-OH kinase. Nature 407:538-541.

Steward O (1997) mRNA localization in neurons: a multipurpose mechanism? Neuron 18:9-12.

Steward O, Falk PM (1991) Selective localization of polyribosomes beneath developing synapses: a quantitative analysis of the relationships between polyribosomes and developing synapses in the hippocampus and dentate gyrus. J Comp Neurol 314:545-557.

Steward O, Schuman EM (2001) Protein synthesis at synaptic sites on dendrites. Annu Rev Neurosci 24:299-325.

Tang SJ, Reis G, Kang H, Gingras AC, Sonenberg N, Schuman EM (2002) A rapamycin-sensitive signaling pathway contributes to long-term synaptic plasticity in the hippocampus. Proc Natl Acad Sci USA 99:467-472.

Tian QB, Nakayama K, Okano A, Suzuki T (1999) Identification of mRNAs localizing in the postsynaptic region. Mol Brain Res 72:147-157.

Tojima T, Yamane Y, Takahashi M, Ito E (2000) Acquisition of neuronal proteins during differentiation of NG108-15 cells. Neurosci Res 37:153-161.

Woolley CS (1999) Effects of estrogen in the CNS. Curr Opin Neurobiol 9:349-354.

Woolley CS, McEwen BS (1992) Estradiol mediates fluctuation in hippocampal synapse density during the estrous cycle in the adult rat. J Neurosci 12:2549-2554.

Yankova M, Hart SA, Woolley CS (2001) Estrogen increases synaptic connectivity between single presynaptic inputs and multiple postsynaptic CA1 pyramidal cells: a serial electron-microscopic study. Proc Natl Acad Sci USA 98:3525-3530.

Yano S, Tokumitsu H, Soderling TR (1998) Calcium promotes cell survival through CaM-K kinase activation of the protein kinase B pathway. Nature 396:584-587.

Zhang W, Vazquez L, Apperson M, Kennedy MB (1999) Citron binds to PSD-95 at glutamatergic synapses on inhibitory neurons in the hippocampus. J Neurosci 19:96-108.

Znamensky V, Akama KT, McEwen BS, Milner TA (2003) Estrogen levels regulate the subcellular distribution of phosphorylated Akt in hippocampal CA1 dendrites. J Neurosci 23:2340-2347. 